\title{
STRATEGI ADAPTASI MASYARAKAT TERHADAP SAMPAH LIMBAH RUMAH TANGGA DENGAN MENGAPLIKASIKAN 3R (RECYCLE, REUSE, DAN REDUCE) DI DESA JEROWARU
}

Fiad Leo Zambana ${ }^{1 *}$, Ismania ${ }^{2}$, Virgina Nita Yosmeniar ${ }^{3}$, Varadibalchwanto ${ }^{4}$, Dina Ayu Lestari ${ }^{5}$, Nurul AenSofiatun ${ }^{6}$, Desi Maharani ${ }^{7}$, M.Taufiq Kurahmat ${ }^{8}$, Saparudin ${ }^{9}$, Muhammad Sukronulhadi ${ }^{10}$, Baiq Rani Dewi Wulandani ${ }^{11 *}$

\author{
${ }^{1}$ Fakultas Tehnik, Universitas Mataram, Mataram, 33125 \\ ${ }^{2}$ Fakultas IlmuSosial dan Politik, Universitas Mataram, Mataram, 33125 \\ ${ }^{3}$ Fakultas Matematika dan IPA, Universitas Mataram, Mataram, 33125 \\ ${ }^{4}$ Fakultas Hukum, Universitas Mataram, Mataram, 33126 \\ ${ }^{5}$ Fakultas Ekonomi dan Bisnis, Universitas Mataram, Mataram, 33126 \\ 6,8 Fakultas Pertanian, Universitas Mataram, Mataram, 33126 \\ 7,10Fakultas Keguruan dan IImu Pendidikan, Universitas Mataram, Mataram, 33126 \\ ${ }^{9}$ Fakultas Peternakan , Universitas Mataram, Mataram, 83126 \\ ${ }^{11}$ Dosen Peternakan, Fakultas Peternakan, Universitas Mataram, Mataram \\ *Co-Author Email: rani.wulandani@gmail.com
}

\begin{abstract}
ABSTRAK. Desa Jerowaru, Kecamatan Jerowaru, merupakan salah satu desa penghasil pertanian dan perikanan di Kabupaten Lombok Timur. Potensi sumber daya alam di Desa Jerowaru berupa produk olahan terasi yang sudah terkelola dengan cukup baik, hanya saja yang menjadi masalah adalah hak cipta. Selain produk terasi Desa Jerowaru juga merupakan desa pengahasil tembakau, namun masyarakat Desa Jerowaru sudah pintar dalam memasarkan hasil pertanian mereka. Masalah yang tidak lepas dari berkembangnya sumber daya alam yaitu terkait dengan limbah rumah tangga baik limbah sampah organik dan anorganik. Kendala yang dihadapi oleh masyarakat adalah kurangnya tingkat kesadaran tentang pengelolaan sampah, disamping kurangnya sarana prasana yang memadai terutama belum adanya tempat pembuangan atau mesin penghancur sampah (alat daur ulang sampah organik/anorganik). Salah satu solusi yang dapat dilakukan untuk mengatasi kendala tersebut adalah dengan mengadakan sosialasi terhadap kesadaran untuk pemanfaatan limbah sampah dan pelatihan pembuatan kompos serta kerajinan tangan. Tujuan dari program ini adalah agar masyarakat Desa Jerowaru mampu beradaptasi dalam membuat pupuk kompos dengan bahan utama sampah organik. Metode yang digunakan adalah persiapan program, sosialisasi dan pelatihan, pembuatan produk, pemanfaatan, monitoring, dan mengevaluasi. Hasil dari program pemberdayaan masyarakat ini adalah kelompok tani Jerowaru yang diharapkan dapat mampu beradaptasi dengan penggunaan 3R. Selain itu, ibu rumah tangga juga menjadi sasaran agar dapat menggunakan kembali sampah anorganik dengan tujuan agar mampu membuat kerajinan tangan dari bahan utama sampah anorganik.
\end{abstract}

Kata Kunci: desa Jerowaru, sampah,3R

ABSTRACT. Jerowaru Village, is one of the agricultural and fishery producing villages in East Lombok Regency. Potencyof natural resourcesin Jerowaru village is shrimp paste products which has been manage well, but the problem is copyright issues. Jerowaru village is producing tobacco, but Jerowaru village already manage well the tobacco products. The growing potential of natural resources is directly proportional to the problem caused. The problem that cannot be separated from the development of natural resources, which is related to organic and anorganic household waste. Constraints faced by the community are the lack of 
awareness about waste management, in addition to the lack of adequate infrastructure facilities, especially the absence of landfills or garbage crushing machines (organic / inorganic waste recycling equipment). One of solution that can be done to overcome these obstacles is by conducting education on waste utilization and training in making compost and handycraft. The aim of this program is to empower the Jerowaru Village community in making compost using organic waste. The methods used are program preparation, socialization and training, product making, utilization, monitoring, and evaluation. The result of this community program is that the Jerowaru farmer group has the potential to be able to adapt with $3 R$. The household Jerowaru village become one of the target to be able to adapt with anorganic household waste. With the aim of being able to make handicraft from the main ingridientsof anorganic waste..

Keyword: Jerowaru Village, Waste, $3 R$

\section{PENDAHULUAN}

Sampah pada dasarnya merupakan suatu bahan yang terbuang atau dibuang dari suatu sumber hasil aktivitas manusia maupun proses-proses alam yang tidak mempunyai nilai ekonomi, bahkan dapat mempunyai nilai yang negatif karena dalam penanganannya baik untuk membuang atau membersihkannya memerlukan biaya yang cukup besar.

Di Desa jerowaru Sampah dan pengelolaannya menjadi masalah tersendiri bagi pihak pemerintah setempat, berbanding terbalik dengan potesi yang terdapat di Desa Jerowaru sampah justru menjadi masalah yang cukup serius. Bagaimana tidak,nyaris di sepanjang jalan Jerowaru dimana ada lahan kosong maka akan menjadi tempat pembuangan sampah oleh masyarakat sekitar, padahal pihak pemerintah Desa Jerowaru sudah menyediakan Tempat Pembuangan Sampah (TPS). Namun masih saja ada masyarakat yang membuang sampah disembarang tempat terutama limbah sampah rumah tangga. Tak hanya di pinggir jalan atau lahan kosong yang menjadi sasaran empuk bagi warga setempat untuk membuang sampah, sungai pun tak luput menjadi tempat bagi warga untuk membuang sampah maka tak heran jika ancaman banjir bisa terjadi kapan saja.Hal Ini membuktikan bahwa kurangnya kepedulian masyarakat terhadap masalah yang akan ditimbulkan dari sampah.

Jika tidak dilakukan penanganan yang baik maka akan mengakibatkan terjadinya perubahan keseimbangan lingkungan yang merugikan atau tidak diharapkan sehingga dapat mencemari lingkungan, baik terhadap tanah, air dan udara. Oleh karena itu mahasiswa KKN Universitas Mataram yang ditugaskan di Desa Jerowaru menjadikan masalah sampah ini sebagai program utama yang menawarkan penanganan untuk mengatasi masalah sampah dengan dua program utama yakni pemanfaatan sampah Organik menjadi pupuk kompos dan pupuk cair, dan pemanfaatan sampah Anorganik yang didaur ulang menjadi produk kerajinan tangan yang nantinya dapat memiliki nilai jual. Hal ini dilakukan agar mengurangi atau meminimalisir jumlah sampah yang ada.

Dimulai dengan 1) Mengajak Ibu rumah tangga untuk memilah antara sampah organik dan anorganik, 2) Mengadakan sosialisasi tentang bagaimana pengolahan sampah Organik dan Anorganik. 3) Penyuluhan sampah Organik dan Anorganik menjadi produk pupuk kompos, pupuk cair dan kerajian tangan dengan pemilihan cara yang tepat serta partisipasi aktif dari masyarakat. 


\section{Jurnal Warta Desa}

www.jwd.unram.ac.id

Vol. 1 NO. 1 April 2019

\section{METODE PELAKSANAAN}

\section{Waktu Pelaksanaan}

\section{Tempat}

Mingggu ke 1 (04 februari 2019) Desa Jerowaru, Kecamatan Jerowaru, sampai minggu ke 5 (10 maret Kabupaten Lombok Timur. 2019)

\section{Alat dan Bahan}

\begin{tabular}{lll}
\hline No & \multicolumn{1}{c}{ Alat } & \multicolumn{1}{c}{ Bahan } \\
\hline 1 & Ember plastik & Air \\
\hline 2 & Parang & Buah busuk \\
\hline 3 & Karung & Sayur busuk \\
\hline 4 & Pengaduk & Daun kering \\
\hline 5 & Gunting & Gula merah \\
\hline 6 & Kater & EM4 \\
\hline 7 & Isolasi & Air kelapa \\
\hline 8 & Kawat & Air cucian beras \\
\hline 9 & Lem tembak & Plastik bekas \\
\hline 10 & Steples & Bungkus kopi \\
\hline 11 & Sarung tangan & \\
\hline 12 & Masker & \\
\hline
\end{tabular}

\section{Prosedur Kerja Pembuatan Pupuk Organik Cair}

\begin{tabular}{cl}
\hline No & \multicolumn{1}{c}{ Langkah kerja } \\
\hline 1 & Mempersiapkan alat dan bahan \\
\hline 2 & Mengaluskan/mencacah sampah organik \\
\hline 3 & $\begin{array}{l}\text { memasukan Sampah yang sudah dihaluskan, Air, EM4, dan gula } \\
\text { kedalam Ember }\end{array}$ \\
\hline 4 & Mencampur dan mengaduk Semua bahan \\
\hline 5 & Menutup ember dengan erat \\
\hline 6 & Mendiamkan Selama 2 minggu \\
\hline 7 & Menyaring pupuk yang sudah terfermentasi \\
\hline 8 & Mengemas dalam wadah baru \\
\hline
\end{tabular}

\section{Prosedur Kerja Pembuatan Pupuk Kompos}

\begin{tabular}{cl}
\hline No & \multicolumn{1}{c}{ Langkah kerja } \\
\hline 1 & Mempersiapkanalat dan bahan \\
\hline 2 & Mencacah sampahorganik \\
\hline 3 & Campurkan air, gulamerah, dan EM4 kedalam ember \\
\hline 4 & Campurkanbahandengansampah yang sudahdicacah \\
\hline 5 & $\begin{array}{l}\text { Masukkan sampahorganik } \\
\text { sudahdicampurdenganbahancairkedalamkarung dan tutuprapat }\end{array}$ \\
\hline 6 & Diamkanselama minggu tanpa terkena sinar matahari \\
\hline 7 & $\begin{array}{l}\text { Mengemas pupuk kompos ke wadah baru jika sudah selesai proses } \\
\text { fermentasi }\end{array}$ \\
\hline
\end{tabular}




\section{Prosedur Kerja Pembuatan Kerajinan Tangan Dari Sampah Anorganik}

\begin{tabular}{ll}
\hline No & \multicolumn{1}{c}{ Langkah kerja } \\
\hline 1 & Mempersiapkan alat dan bahan \\
\hline 2 & Membersihkan semuabahan agar terlihat layak pakai \\
\hline 3 & Menyetrika plastik bekas yang sudah dibersihkan hingga menjadi kaku, \\
\hline 4 & Setelah kaku membuat pola lingkaran \\
\hline 5 & Menggunting pola lingkaran \\
\hline 6 & Dilipat dan digunting hingga menjadi bentuk pola bunga \\
\hline 7 & Setelah berbentuk pola bunga, kemudian disusun hingga menjadi bunga \\
\hline 8 & Untuk tangkai bunga menggunakan kawat \\
\hline 9 & $\begin{array}{l}\text { Tangkai dilapisi plastik warna hijau dan diberi lem tembak agar tangkainya } \\
\text { erat dengan plastic }\end{array}$ \\
\hline 10 & $\begin{array}{l}\text { Mengemas ke dalam wadah baru atau menggunakan pot agar terlihat } \\
\text { cantik. }\end{array}$ \\
\hline
\end{tabular}

\section{Bentuk Kegiatan}

\begin{tabular}{cl}
\hline No & \multicolumn{1}{c}{ Bentuk kegiatan } \\
\hline 1 & $\begin{array}{l}\text { Persiapan program dimulai dengan mempersiapkan segala keperluan } \\
\text { program utama seperti menentukan lokasi pembuatan pupuk kompos dan } \\
\text { berlatih membuat kerajinan tangan, serta membuat plang tempat } \\
\text { pembuangan sampah }\end{array}$ \\
\hline 2 & $\begin{array}{l}\text { Sosialisasi tentang sampahdengan mengundang masyarakat dan instansi } \\
\text { terkait dengan tentang sampahdengan mengundang masyarakat dan instansi }\end{array}$ \\
& terkait dengan masalah kebersihan di Desa Jerowaru \\
\hline 3 & $\begin{array}{l}\text { Pelatihan Pembuatan pupuk cair, pupuk kompos, dan kerajinan tangan } \\
\text { dimulai dengan mempersiapkan bahan dan alat yang diperlukan seperti }\end{array}$ \\
& $\begin{array}{l}\text { sampah Organik dan Anorganik yang telah dipilah sebelumnya. Kemudian } \\
\text { mengajak mayarakat setempat untuk berpartisipasi dalam praktik pembuatan } \\
\text { pupuk dan melibatkan ibu-ibu serta anak SD di Desa Jerowaru untuk } \\
\text { membuat kerajinan tangan }\end{array}$ \\
\hline 4 & Monitoring dan evaluasi berjalan lancar selama proses KKN. \\
\hline
\end{tabular}

\section{Metode Pengumpulan dan Analisis Data}

Metode pengumpulan data pada program ini adalah dengan survei jumlah sampah rumah tangga dan penggunaan pupuk organik dan penggunansampahanorganik. Analisis data menggunakan deskriptif kualitatif

\section{HASIL DAN PEMBAHASAN}

Program utama yang dijalankan cukup terstruktur dan melibatkan masyarakat secara langsung, mulai dari mengadakan sosialisasi tentang pengolahan sampah organik dan anorganik menjadi pupuk kompos dan pupuk cair serta menjadi kerajinan tangan sampai dengan bagaimana cara pembuatan produk olahan dari sampah itu sendiri. Semua dilakukan dan di praktikan secara langsung dengan melibatkan masyarakat Jerowaru sendiri. 


\section{Pelaksanaan Strategi Terhadap Masyarakat}

Kegiatan strategiterhadap masyarakat ini dimulai dengan persiapan program yang meliputi survei lokasi. Hasil survei menujukan bahwa kendala yang dihadapi masyarakat Jerowaru antara lain 1) tidak adanya pemberitahuan secara tertulis dimana tempat pembuangan sampah sehingga msyarakat membuang sampah di tempat yang tidak seharusnya 2) banyak volume sampah setiap harinya, 3) tidak adanya alat penghancur sampah serta kendaraan pengangkut sampah 4) Tahap selanjutnya adalah persiapan monitoring dan evaluasi yaitu pengetahuan masyarakat, selanjutnya perijinan dan pembahasan program bersama masyarakat Jerowaru, Kecamatan Jerowaru, Kabupaten Lombok Timur.

\section{Pelatihan Pembuatan Pupuk Kompos dan Pupuk Cair dari Sampah Organik}

Penyuluhan sampah dan pelatihan pembuatan pupuk organik Kompos dan pupukcairdi Desa Jerowaru dilakukan di depanposyandu. Pelatihan ini diadakan agar mayarakat Jerowaru dapat mengetahui prosedur pembuatan pupuk kompos dan pupuk cair, mengetahui manfaat dari pupuk kompos dan pupukcair dan untuk menumbuhkan serta meningkatkan kesadaran masyarakat mengenai kebersihan lingkungan agar dapat membedakan jenis sampah mana yang dapat didaur ulangdan tidak dapat didaur ulang. Serta sampah yang dapat dimanfaatkan agar berfungsinya.
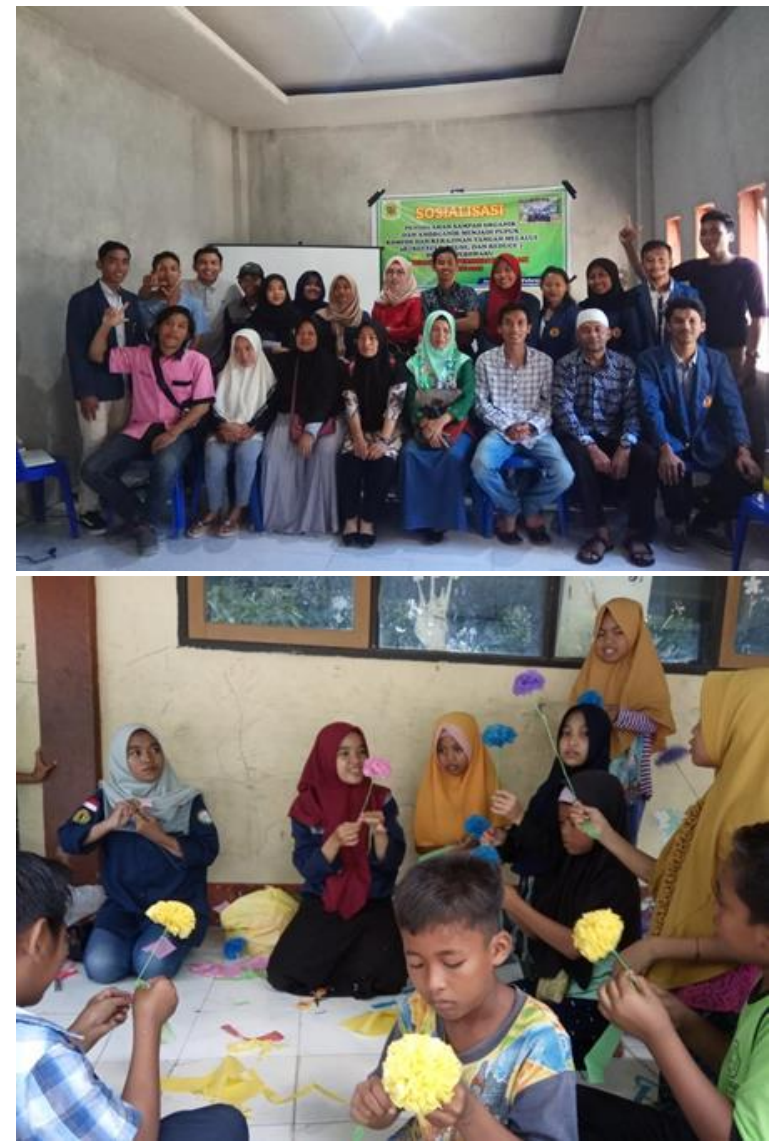

Gambar 1. Kegiatan Pembinaan Masyarakat 


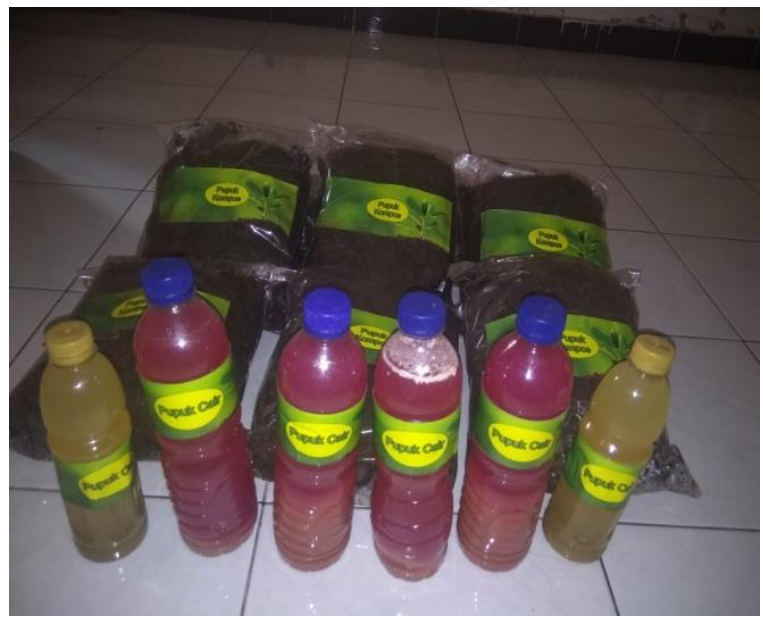

Gambar 2. Produk Pupuk Organik

Pelatihan kedua yaitu mengenai membuat kerajinan tangan dari sampah anorganik yaitu pembuatan bunga dari plastik-plastik bekas yang bertempat di SDN 3 Jerowaru yang dimana kita melatih untuk kelas III dan kelas IV. Kegiatan ini dijadwalkan setiap hari selasa, dari tanggal 5 Februari sampai dengan tanggal 12 Maret. Selain mengajak anak-anak SD untuk membuat kerajinan tangan kegiatan ini juga melibatkan ibu-ibu serta remaja di Desa Jerowaru.Kegiatan ini dilaksankan dengan memanfaatkan sampah-sampah anorganik sebagai upaya pengelolaan sampah dapat berguna bagi masyarakat khususnya masyarakatdi Desa Jerowaru.pelatihan ini bertujuan untuk membuat sekaligus mengetahui proses yang efektif dalam pembuatan bunga dari sampah plastik bekasini. Sampah plastik yang telah terbuat menjadi bunga bias dipasarkan dan mendapatkan keuntungan.

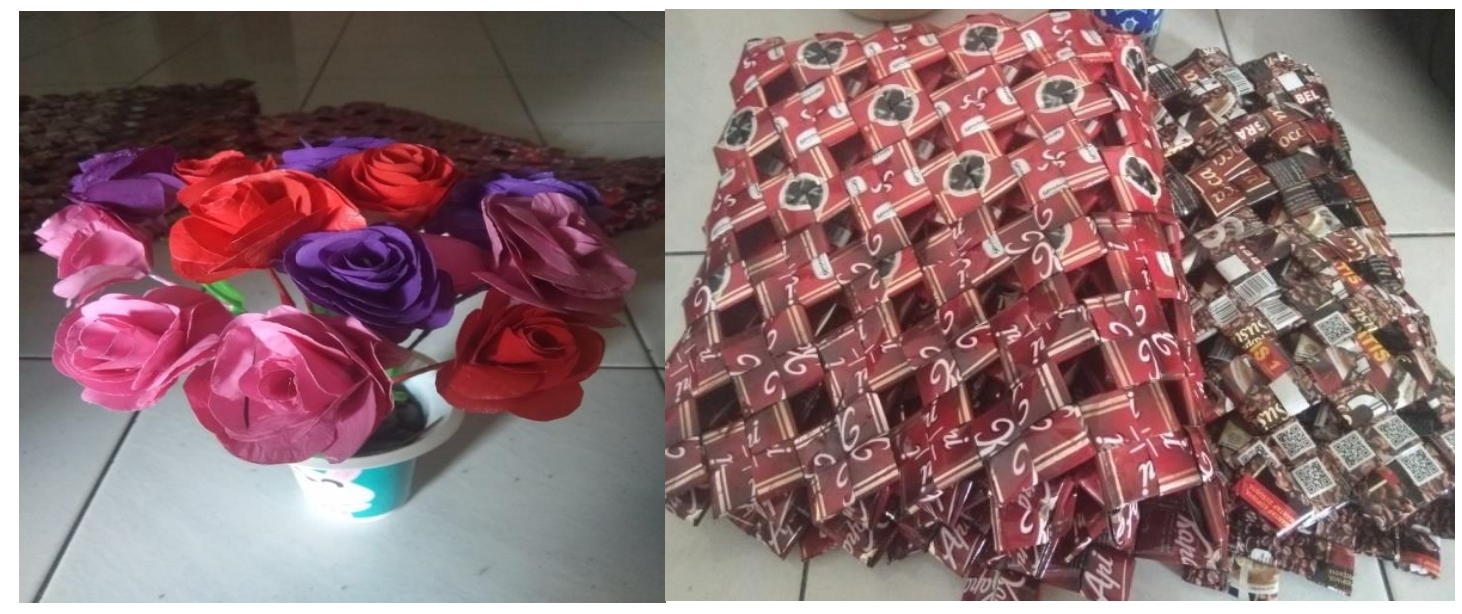

Gambar 3. Produk kerajinan dari sampah plastik 


\section{Monitoring dan Evaluasi}

Monitoring dan evaluasi dilakukan bersamaan dengan pedampingan program. Hasil monitoring berkelaanjutan. Evaluasi program secara umum menunjukkan bahwa mahasiswa KKN Universitas Mataram periode 2019 mampu memberdayakan sampah sebagai bahan untuk membuat pupuk organik (kompos), pupuk cair dan kerajinan tangan seperti taplak meja dari bungkusan kopi. Selama proses KKN berlangsung semua program kerja sudah berjalan dengan semestinya, akan tetapi masih ada beberapa kegiatan lain yang belum berjalan dengan maksimal, karena waktu yang sangat terbatas yaitu 45 hari. Oleh karena itu kegiatan-kegiatan yang belum terealisasikan bisa dilanjutkan oleh masyarakat desa Jerowaru, karena sebelumnya juga sebagian dari masyarakat desa Jerowaru telah diajarkan juga bagaimana cara membuat dan menyelesaikan kegiatan-kegiatan tersebut.

\section{KESIMPULAN}

Selama proses KKN berlangsung telah menghasilkam produk pupuk kompos dan cair dari hasil olahan sampah organik seperti, daun-daun dan buah busuk kemudian untuk kerajianan tangan yang diolah dari sampah anorganik seperti, plastic bekas, botol minuman bekas dll. Kegiatan pengolahan sampah tentu melibatkan peran aktif masyarakat sekitar dengan cara mengadakan sosialisasi tentang pengolahan sampah agar menjadi produk yang berguna serta nantinya dapat memiliki nilai jual. Diharapkan agar kedepannya masyarakat dapat mengelola sampah dengan baik dan bijaksana agar tercipta lingkungan yang sehat dan indah.

\section{REFERENSI}

Apriadji, Wied Harry.1994. Memproses sampah. Jakarta: Penebar Swadaya.

Moerdjoko S, Widyatmoko, 2012, Menghindari,mengolah dan menyingkirkan sampah,Cet.1, PT. Dinastindo Adiperkasalnternasional, Jakarta.

Parnata, Ayub.S. 2004. Pupuk Organik Cair. Jakarta : PT Agromedia Pustaka. Hal 15-18.

Rohendi, E. 2005. Lokakarya Sehari Pengelolaan Sampah Pasar DKI Jakarta, sebuah prosiding. Bogor, 17 Februari 2005.

Siburian, R, 2008, Pengaruh Konsentrasi danWaktu Inkubasi EM4 Terhadap KualitasKimia Kompos, Jurusan Kimia, Fak. Sainsdan Teknik Universitas Nusa Cendana ,Kupang.

Sukamto, 2007, Membuat Pupuk Kompos Cair, Cetakan ketiga, AgromediaPustaka, Jakarta.

Suriadikarta, Didi Ardi., Simanungkalit, R.D.M. (2006).PupukOrganik dan PupukHayati. Jawa Barat: Balai Besar Penelitian dan Pengembangan Sumber daya Lahan Pertanian. Hal 2.

Sutanto, Rachman. (2002). Pertanianorganik: Menuju Pertanian Alternatif dan Berkelanjutan. Jakarta: Kanisius.

Al-Mujahid, Riezwan. 2 Desember 2012. Pengertian Limbah.

Gelbert, 1996. Pengelolaan Sampah. Malang: PPPGT/VEDC Malang. 